\title{
Mesomorphism Dependence on Cis-Trans Configuration and Varying Terminal/Lateral Group
}

\author{
G.N.Bhola and U.C. Bhoya \\ Department of Chemistry, Saurashtra University, Rajkot-360005, Gujarat, India. \\ Corresponding Author: \\ E-mail address:bholagn@gmail.com, “drucbhoya@gmail.com
}

Keywords: Mesomorphism, Smectic, Nematic, Monotropy, Enantiotropy.

\begin{abstract}
A chalconyl trans vinyl ester homologous series of thermotropic liquid crystals RO$\mathrm{C}_{6} \mathrm{H}_{4}-\mathrm{CH}=\mathrm{CH}-\mathrm{COO}-\mathrm{C}_{6} \mathrm{H}_{4}-\mathrm{CH}=\mathrm{CH}-\mathrm{CO}-\mathrm{C}_{6} \mathrm{H}_{3}\left(\mathrm{OCH}_{3}\right)_{2}$ meta-para is synthesized and studied with a view to understand and establish the relation between molecular structure and mesomorphism or mesomorphic behaviors. Novel homologous series consists of thirteen homologues $\left(\mathrm{C}_{1}\right.$ to $\left.\mathrm{C}_{18}\right)$. First five $\left(C_{1}\right.$ to $\left.C_{5}\right)$ homologues are nonmesogenic. Rest of the homologues $\left(C_{6}\right.$ to $\left.C_{18}\right)$ homologues is mesogenic. Monotropically smectogenic character appears from $\mathrm{C}_{6}$ to $\mathrm{C}_{10}$ homologue and $\mathrm{C}_{12}$ to $\mathrm{C}_{18}$ homologues are enantiotropically smectogenic. Nematogenic property is totally absent throughout a series. Textures of smectic phase are of the type smectic A or C. Transition curves of a phase diagram behaved in normal manner. Analytical, spectral and thermal data supports the molecular structures of homologues. Odd-even effect is observed for Sm-I/I-Sm transition curve. Thermal stability for smectic is $93.7^{\circ} \mathrm{C}$ and the mesomorphic phase lengths from enantiotropic homologues for smectic from minimum to maximum is $6.0^{\circ} \mathrm{C}$ to $28.0^{\circ} \mathrm{C}$ at the $\mathrm{C}_{12}$ and $\mathrm{C}_{18}$ homologue respectively. Series is smectogenic without exhibition of nematic property. The group efficiency order on the basis of thermal stability is derived; from comparative study of present series and analogous series.
\end{abstract}

\section{Introduction}

The study of mesomorphism and mesomorphic behaviors of liquid crystalline (LC) compounds [1] is one of the important and interesting aim, object and view to predict and exploited their characteristics in the benefit of mankind and living creatures or matters $[2,3,4,5,6,7,8,9,10]$. Therefore the object in view to understand and establish the effect of molecular structure $[11,12,13,14,15,16]$ on liquid crystal properties with reference to varying flexibility and cis-trans molecular configuration as a consequence of combined effect of molecular rigidity and flexibility $[17,18,19,20,21]$. Present investigation is planned to synthesized novel LC compounds through homologous series containing three phenyl rings bonded through two central bridges $-\mathrm{CH}=\mathrm{CH}-$ $\mathrm{COO}$ - and $-\mathrm{CH}=\mathrm{CH}-\mathrm{CO}$ - and varying $-\mathrm{OR}$ terminal with fixed lateral $-\mathrm{OCH}_{3}$ group throughout a novel series of proposed investigations. Study will include the characterization of novel compounds by thermal, analytical and spectral data. Results of the evaluated data will be discussed in terms of molecular rigidity and flexibility. The conclusions will include group efficiency order for smectic and nematic and probable importance and probable possibility of application will be suggested for the researchers working in application fields of present investigation. Number of homologous series have been reported till the date $[22,23,24,25,26,27,28,29]$.

\section{Experimental}

\section{Synthesis}

4-n-Alkoxybenzaldehydes were synthesized by refluxing 4-hydroxybenzaldehyde (1 equiv.) with corresponding n-alkyl bromides ( 1 equiv.) in the presence of potassium carbonate ( 1 equiv.) and acetone as a solvent [30]. The resulting 4-n-alkoxybenzaldehydes were reacted with malonic acid (1.2 equiv.) in the presence of 1-2 drops piperidine as catalyst and pyridine as solvent to yield corresponding trans 4-n-alkoxy cinnamic acids (A) [31]. $\beta$-4-Hydroxy phenyl $\alpha-3$ '-4' 
dimethoxybenzoyl ethylene (B)was prepared by an established method [32] M.P. $148.0{ }^{\circ}$ C, Yield$65.5 \%$. Coupling of compound A and compound B is done by steglich esterification to yield $\beta-4-(4 '-$ n-alkoxy cinnamoyloxy) phenyl $\alpha-3$ "-4"dimethoxy benzoyl ethylene [33].

The synthetic route to the novel homologous series is under mentioned in scheme-1.

\section{Scheme-1: Synthetic route to the novel series}

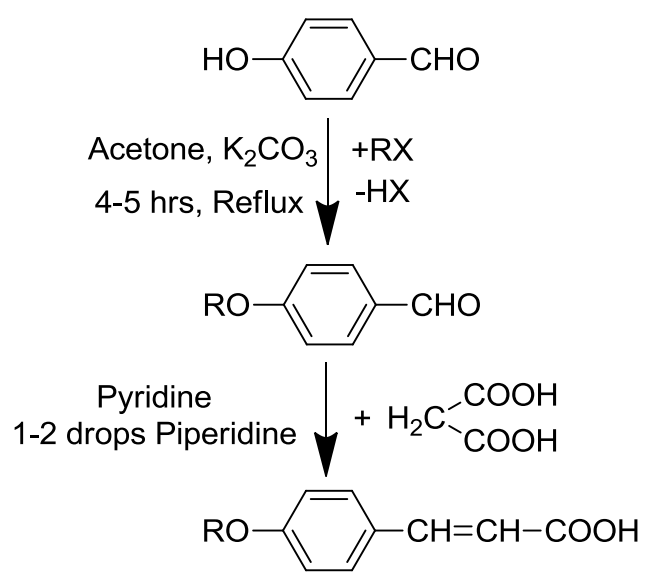

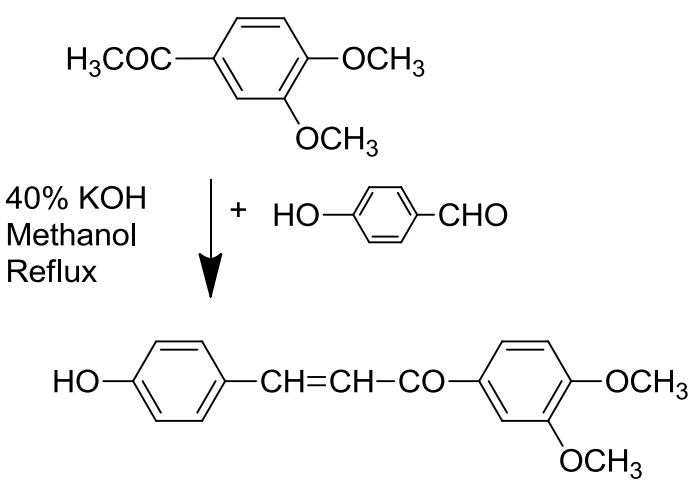

[B]

[A]

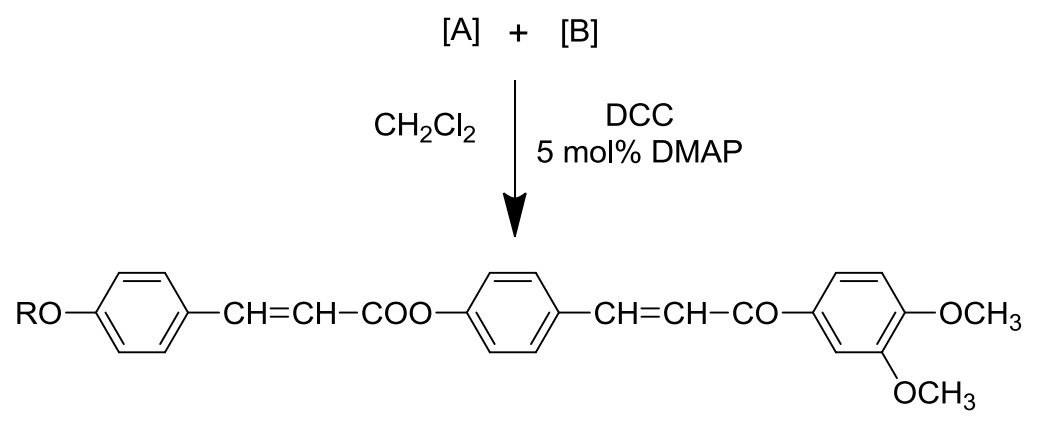

Where, $\mathrm{R}=\mathrm{C}_{\mathrm{n}} \mathrm{H}_{2 \mathrm{n}+1}, \mathrm{n}=1$ to $8,10,12,14,16$ and 18

\section{Characterization}

Some of members of a novel series as the representative member of a series were characterized by elemental analysis (Table-1), Infrared spectroscopy, ${ }^{1} \mathrm{H}$ NMR spectra and mass spectroscopy. Microanalysis was performed on EuroEA Elemental Analyzer. IR spectra were recorded on Shimadzu FTIR Model-IRAffinity-1S (MIRacle 10), ${ }^{1}$ HNMR spectra were recorded on Bruker spectrometer using $\mathrm{CDCl}_{3}$ as a solvent and mass spectra were recorded on Shimadzu GCMS Model No.QP-2010.

\section{Analytical data}

Table-1: Elemental analysis for (1) Pentyloxy (2) Heptyloxy (3) Dodecyloxy derivatives

\begin{tabular}{|c|c|c|c|c|c|c|c|}
\hline \multirow{2}{*}{$\begin{array}{c}\text { Sr. } \\
\text { No. }\end{array}$} & \multirow{2}{*}{$\begin{array}{c}\text { Molecular } \\
\text { formula }\end{array}$} & \multicolumn{3}{|c|}{ Elements \%Found } & \multicolumn{3}{c|}{ Elements \%Calculated } \\
\cline { 3 - 8 } & $\mathrm{C}$ & $\mathrm{H}$ & $\mathrm{O}$ & $\mathrm{C}$ & $\mathrm{H}$ & $\mathrm{O}$ \\
\hline 1 & $\mathrm{C}_{31} \mathrm{H}_{32} \mathrm{O}_{6}$ & 74.44 & 6.42 & 19.14 & 74.38 & 6.44 & 19.18 \\
\hline 2 & $\mathrm{C}_{33} \mathrm{H}_{36} \mathrm{O}_{6}$ & 75.05 & 6.83 & 18.12 & 74.98 & 6.86 & 18.16 \\
\hline 3 & $\mathrm{C}_{38} \mathrm{H}_{46} \mathrm{O}_{6}$ & 76.28 & 7.71 & 16.00 & 76.22 & 7.74 & 16.03 \\
\hline
\end{tabular}




\section{Spectral Data}

\section{${ }^{1}$ HNMR in ppm for Methyloxy Derivative}

$3.87\left(\mathrm{~s}, 3 \mathrm{H},-\mathrm{CH}_{3}\right.$ of $-\mathrm{OCH}_{3}$ group of cinnamate ring), $3.94\left(\mathrm{~s}, 6 \mathrm{H}\right.$, two $-\mathrm{OCH}_{3}$ groups of dimethoxy phenyl ring), 7.38-7.42 (d,1H, $-\mathrm{C} \underline{H}=\mathrm{CH}-\mathrm{COO}-), 6.49-6.53(\mathrm{~d}, 1 \mathrm{H},-\mathrm{CH}=\mathrm{C} \underline{\mathrm{H}}-\mathrm{COO}), 8.08-8.10(\mathrm{~d}, 1 \mathrm{H}$, $-\mathrm{C} \underline{\mathrm{H}}=\mathrm{CH}-\mathrm{CO}-), 7.55-7.57$ (d,1H, $-\mathrm{CH}=\mathrm{C} \underline{\mathrm{H}}-\mathrm{CO}-)$, 7.24-7.26 \& 7.84-7.88 (4H, middle phenyl ring), 6.90-6.94 \& 7.60-7.63 (4H, phenyl ring with single methoxy group), 7.17-7.18, 7.31-7.33 \& 7.77$7.81(3 \mathrm{H}$, phenyl ring with two methoxy group), The NMR data are reliable with the molecular structure.

\section{${ }^{1}$ HNMR in ppm for Propyloxy Derivative}

1.03-1.08 (t,3H, $-\mathrm{CH}_{3}$ of $-\mathrm{OC}_{3} \mathrm{H}_{7}$ group), 1.80-1.89 (m, $\left.4 \mathrm{H}, \mathrm{CH}_{3}-\mathrm{CH}_{2}-\mathrm{CH}_{2}-\mathrm{O}-\right), 3.97-3.98\left(\mathrm{t}, 2 \mathrm{H},-\mathrm{CH}_{2}-\right.$ $\mathrm{O}-), 3.95$ (s,6H, two $-\mathrm{OCH}_{3}$ groups of dimethoxy phenyl ring), 7.42-7.43 (d,1H, - $\left.\underline{\mathrm{H}}=\mathrm{CH}-\mathrm{COO}-\right)$, 6.49-6.53 (d,1H, -CH=Cㅌ-COO- $), 8.08-8.10(\mathrm{~d}, 1 \mathrm{H},-\mathrm{C} \underline{\mathrm{H}}=\mathrm{CH}-\mathrm{CO}-), 7.54-7.56(\mathrm{~d}, \overline{1} \mathrm{H},-\mathrm{CH}=\mathrm{C} \underline{\mathrm{H}}-$ CO-), 7.26-7.28 \& 7.84-7.88 (4H, middle phenyl ring), 6.90-6.95 \& 7.62-7.66 (4H, phenyl ring with propyloxy group), 7.17-7.18, 7.32-7.34 \& 7.77-7.81 (3H, phenyl ring with two methoxy group), The NMR data are reliable with the molecular structure.

\section{IR in $\mathrm{cm}^{-1}$ for Butyloxy Derivative}

3076 (C-H str. of alkene disubstituted), $2960 \& 2868$ (C-H str. of $\left(-\mathrm{CH}_{2}-\right)_{n}$ group of $\left.-\mathrm{OC}_{4} \mathrm{H}_{9}\right), 1737$ $(\mathrm{C}=\mathrm{O}$ str. of carbonyl carbon of ester group), $1643(\mathrm{C}=\mathrm{O}$ str. of $\alpha, \beta$ unsaturated ketone $), 1587(\mathrm{C}=\mathrm{C}$ str. of alkene), $1508 \& 1421(\mathrm{C}=\mathrm{C}$ str. of aromatic ring), 1357 (C-H bending of alkene disubstituted), 1305 (C-O str. of ether linkage), 1134 (C-O str. of ester group), 972 \& 862 (C-H bending of alkene). The IR data are consistent with the molecular structure.

\section{IR in $\mathrm{cm}^{-1}$ for Decyloxy Derivative}

3068 (C-H str. of alkene disubstituted), 2918 \& $2846\left(\mathrm{C}-\mathrm{H}\right.$ str. of $\left(-\mathrm{CH}_{2}-\right)_{\mathrm{n}}$ group of $\left.-\mathrm{OC}_{10} \mathrm{H}_{22}\right)$, $1732(\mathrm{C}=\mathrm{O}$ str. of carbonyl carbon of ester group), $1651(\mathrm{C}=\mathrm{O}$ str. of $\alpha, \beta$ unsaturated ketone), 1629 $(\mathrm{C}=\mathrm{C}$ str. of alkene), 1593, $1510 \& 1463(\mathrm{C}=\mathrm{C}$ str. of aromatic ring), $1354 \& 1309$ ( $\mathrm{C}-\mathrm{H}$ bending of alkene disubstituted), 1259(C-O str. of ether linkage), 1145 (C-O str. of ester group), $983 \& 829$ (C-H bending of alkene). The IR data are consistent with the molecular structure.

\section{Mass spectra of Ethyloxy Derivative}

m/z (rel.int\%): $458(\mathrm{M})^{+}, 293,175,165,133,118,103,77$

\section{Mass spectra of Heptyloxy Derivative \\ m/z (rel.int\%): $514(\mathrm{M})^{+}, 349,231,175,165,133,118,103,77$}

\section{Results and discussion}

Transition temperatures of novel homologues are relatively lower as compared to the corresponding dimerised trans n-alkoxy cinnamic acids. Extension of a molecule by linking $\beta-4-$ hydroxy phenyl $\alpha-3$ '-4' dimethoxy benzoyl ethylene with trans 4-n-alkoxy cinnamic acid yielded mesomorphic homologues from $\mathrm{C}_{6}$ to $\mathrm{C}_{18}$ derivatives. $\mathrm{C}_{6}$ to $\mathrm{C}_{10}$ homologues are monotropicsmectic and the rest of the homologues $\mathrm{C}_{12}$ to $\mathrm{C}_{18}$ homologues are enantiotropicsmectic. None of the homologue is smectogenic in character. $\mathrm{C}_{1}$ to $\mathrm{C}_{5}$ homologues are nonliquid crystals. Transition temperatures (Table-2) as determined by an optical polarizing microscopy (POM) were plotted against the number of carbon atoms present in n-alkyl chain ' $R$ ' of the left n-alkoxy -OR terminal. 
Table-2: Transition temperatures in ${ }^{\circ} \mathrm{C}$

\begin{tabular}{|c|c|c|c|c|}
\hline $\begin{array}{c}\text { Compound } \\
\text { No. }\end{array}$ & $\begin{array}{c}\text { n-alkyl chain } \\
\mathbf{C}_{\mathbf{n}} \mathbf{H}_{\mathbf{2 n + 1}}(\mathbf{n})\end{array}$ & Sm & $\mathbf{N}$ & Isotropic \\
\hline 1 & 1 & - & - & 166.0 \\
\hline 2 & 2 & - & - & 159.0 \\
\hline 3 & 3 & - & - & 154.0 \\
\hline 4 & 4 & - & - & 161.0 \\
\hline 5 & 5 & - & - & 144.0 \\
\hline 6 & 6 & $(94.0)$ & - & 131.0 \\
\hline 7 & 7 & $(107.0)$ & - & 128.0 \\
\hline 8 & 8 & $(104.0)$ & - & 133.0 \\
\hline 9 & 10 & $(112.0)$ & - & 151.0 \\
\hline 10 & 12 & 91.0 & - & 97.0 \\
\hline 11 & 14 & 80.0 & - & 90.0 \\
\hline 12 & 16 & 71.0 & - & 92.0 \\
\hline 13 & 18 & 68.0 & - & 96.0 \\
\hline
\end{tabular}

Sm- Smectic; N- Nematic; ( ) indicate monotropy

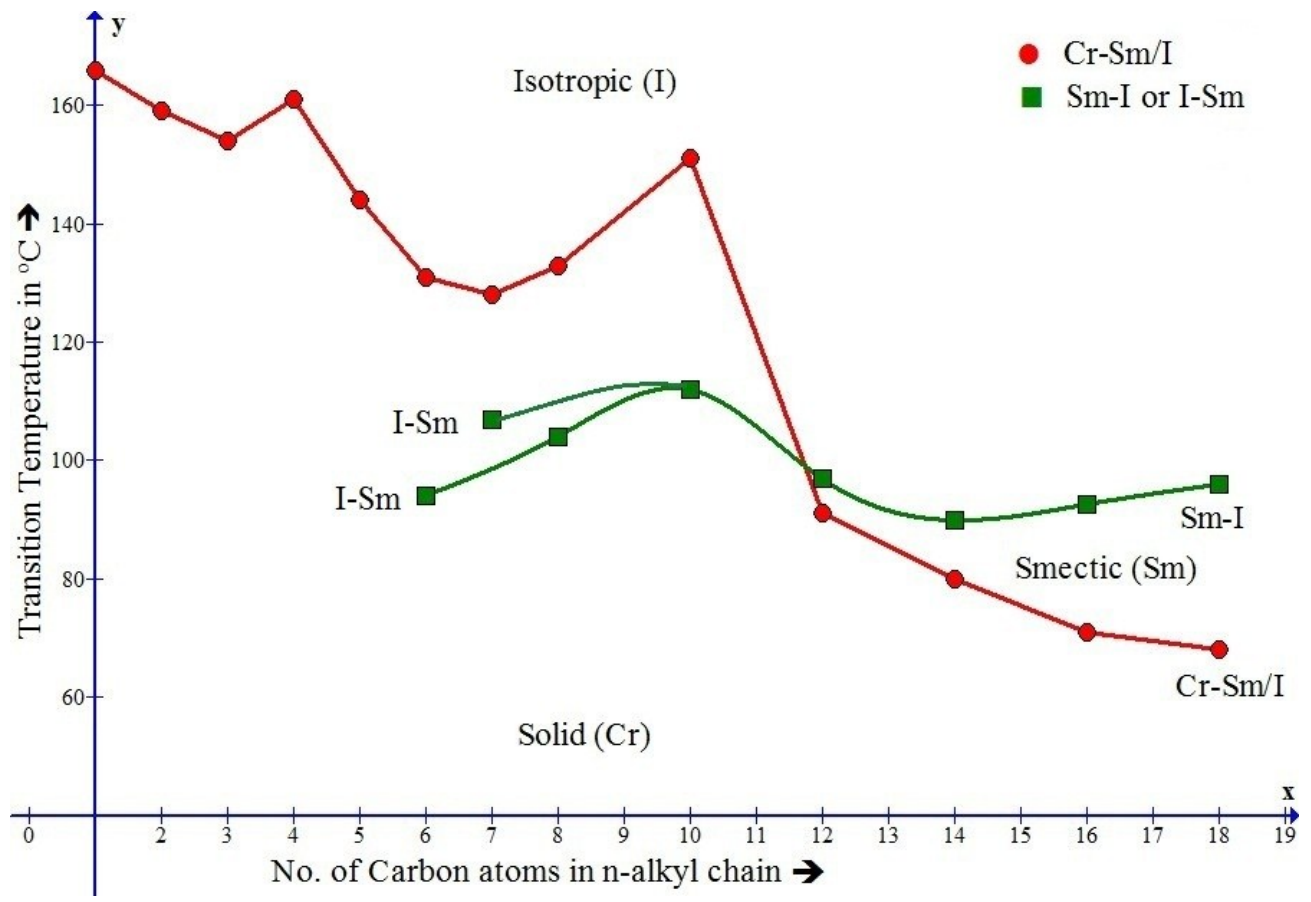

Figure-1: Phase Behavior of Series

Transition curves Cr-Sm/I, Sm-I/I-m are drawn through like or related points as depicted in a phase diagram (Figure-1) showing phase behaviors of a series. Cr-Sm/I transition curve adopted normal zigzag path of rising and falling with overall descending tendency. Sm-I/I-Sm transition curves for odd and even homologues initially rises from $\mathrm{C}_{6}$, then it passes through maxima at $\mathrm{C}_{10}$ and finally descended upto $\mathrm{C}_{14}$ and then ascended by $4.0^{\circ} \mathrm{C}$ to $6.0^{\circ} \mathrm{C}$ for $\mathrm{C}_{16}$ and $\mathrm{C}_{18}$ homologues. Thus, it behaved almost in normal manner, with exhibition of odd-even effect from $\mathrm{C}_{6}$ to $\mathrm{C}_{10}$ homologue. Curves for I-Sm for odd-even members merge into each other at the $\mathrm{C}_{10}$ homologue and then odd-even effect disappears as series is ascended upto $\mathrm{C}_{18}$ homologue. The texture of smectic phase are of the type A or C. Thermal stability for smectic is $93.7^{\circ} \mathrm{C}$ whose mesophase lengths from $6.0{ }^{\circ} \mathrm{C}$ to $28.0{ }^{\circ} \mathrm{C}$ at the $\mathrm{C}_{12}$ and $\mathrm{C}_{18}$ homologues respectively. Mesomorphic properties from homologue to homologue in present series are varied from $C_{6}$ to $C_{18}$ homologue. $C_{1}$ to $C_{5}$ homologues are nonmesogenic. Lowering of transition temperatures and the disappearance of dimerisation of trans n-alkoxycinnamic acids are attributed to the breaking of hydrogen bonding 
between two molecules of carboxylic acids by the process of esterification. The exhibition of smectogenic character is attributed to the suitable magnitudes of intermolecular cohesion by end to end and lateral $-\mathrm{OCH}_{3}$ groups which causes lamellar packing of molecules commencing from $\mathrm{C}_{6}$ homologue to $\mathrm{C}_{18}$ homologue to float the molecules on the surface with sliding layered molecular arrangement either in monotropic or enantiotropic condition. Odd-even effect observed for Sm-I or I-Sm transition curve is due to the sequentially added methylene unit at the n-alkyl chain ' $R$ ' of -OR flexible group. The disappearance of odd-even effect from and beyond $\mathrm{C}_{10}$ homologue is attributed to the coiling bonding or flexing or coupling of longer in alkyl chain or ' $\mathrm{R}$ ' with the major axis of a core structure of a molecule. The non-mesomorphicity observed for $C_{1}$ to $C_{5}$ is due to their high crystallizing tendency arising from low magnitudes of dispersion forces and low magnitudes of dipole-dipole interactions which abruptly breaks crystal lattices and sharply transforms into isotropic liquid directly from crystalline solid with bypassing of LC state, a high order of molecular disorder occur and molecules are randomly oriented in all possible directions. However, on cooling the isotropic mass for $\mathrm{C}_{6}$ to $\mathrm{C}_{10}$ homologues below their isotropic temperature, the monotropic smectic mesophase appears in irreversible manner. None of the $C_{1}$ to $C_{5}$ homologue did exhibit monotropic mesomorphism, but $\mathrm{C}_{12}$ to $\mathrm{C}_{18}$ homologue exhibited smectic mesophase formation enantiotropically in reversible manner due to the presence of highly polar two $-\mathrm{OCH}_{3}$ groups bonded as terminal and lateral groups; the molecular flexibility contributed in combination with flexibility due to -OR group, facilitated to induce smectogenic character in reversible manner. The absence of nematic property is attributed to the weaker or unsuitable magnitudes of end to end intermolecular cohesion and closeness occurred due to meta substituted $-\mathrm{OCH}_{3}$ group, which hindered the nematic mesophase formation but favored smectogenic mesophase formation through the suitable magnitudes of molecular polarizability contribution. The variations in mesogenic properties of present novel series-1 are compared with the structurally similar analogous series-X [34] and Y [35] as mentioned below in figure-2.

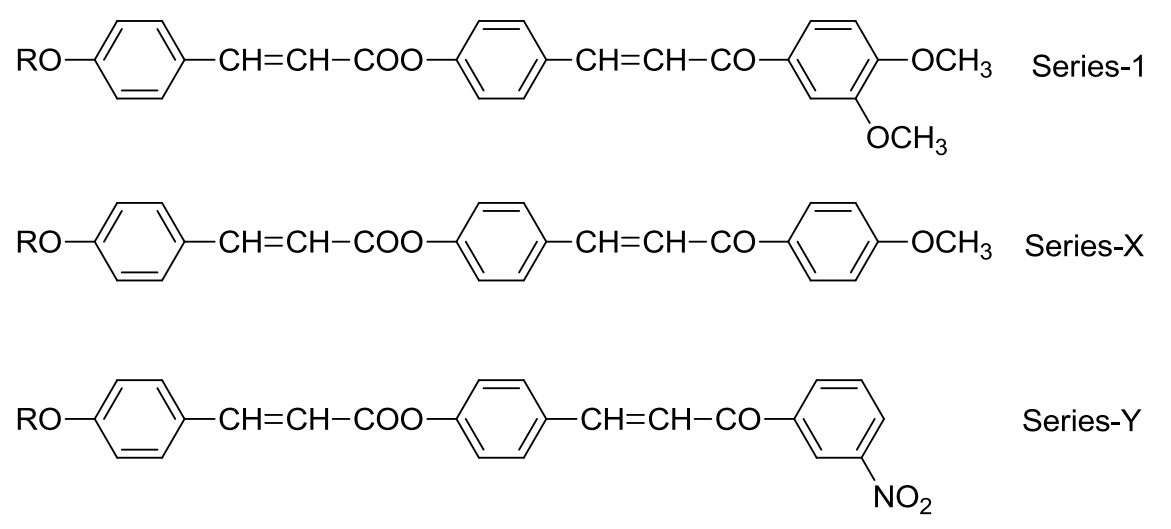

Figure-2: Structurally similar series.

Above novel homologous series-1, $\mathrm{X}$ and $\mathrm{Y}$ appear identical with respect to three phenyl rings, two central bridges and left n-alkoxy (-OR) group for the same homologue from series to series. But they differ with respect to Trans and cis configuration. Present homologous series-1 is of Trans configuration and the homologous series-X and $\mathrm{Y}$ selected for comparison are with cis configuration. Therefore their molecular rigidity differs from series to series keeping the molecular flexibility due to left -OR flexible group unaltered from series to series for the same homologue.Moreover, the right handed groups bonded to third phenyl rig (viz. meta-para dimethoxy $\left(-\mathrm{OCH}_{3}\right)_{2}$, para $-\mathrm{OCH}_{3}$ and meta $-\mathrm{NO}_{2}$ ) differs in polarities and polarizability affecting molecular flexibility for the same homologue from series to series. Thus, variations in mesomorphic properties and mesomorphic behaviors can vary with the changing features and their magnitudes of molecular rigidity and/or flexibility for the same homologue from series to series. Following table-3 represents some thermometric mesogenic properties and behaviors for the present series-1 and series-X and $\mathrm{Y}$ chosen for comparative study. 
Table-3: Relative thermal stabilities in ${ }^{\circ} \mathrm{C}$

\begin{tabular}{|c|c|c|c|}
\hline Series $\rightarrow$ & 1 & $\mathrm{X}$ & $\mathrm{Y}$ \\
\hline Sm-I or I-Sm or Sm-N & 93.7 & - & 154.6 \\
$\left(\mathrm{C}_{12}-\mathrm{C}_{18}\right)$ & & $\left(\mathrm{C}_{5}-\mathrm{C}_{8}\right)$ \\
$\begin{array}{c}\text { Commencement of } \\
\text { Smecticmesophase }\end{array}$ & $\mathrm{C}_{6}$ & - & $\mathrm{C}_{5}$ \\
\hline N-I & - & 164.6 & 163.8 \\
& - & $\left(\mathrm{C}_{5}-\mathrm{C}_{14}\right)$ & $\left(\mathrm{C}_{5}-\mathrm{C}_{16}\right)$ \\
$\begin{array}{c}\text { Commencement of } \\
\text { nematic phase }\end{array}$ & $\mathrm{C}_{5}$ & $\mathrm{C}_{5}$ \\
\hline $\begin{array}{c}\text { Total Mesophase length } \\
\text { range (Sm+N) }\end{array}$ & $6.0\left(\mathrm{C}_{12}\right)$ & $10.0\left(\mathrm{C}_{14}\right)$ & $\begin{array}{c}10.0\left(\mathrm{C}_{16}\right) \\
\text { to } 46.0\left(\mathrm{C}_{6}\right)\end{array}$ \\
\hline
\end{tabular}

Above table-3 represent that

- Present series-1 and $X$ are only smectogenic and only nematogenic respectively, whereas series-Y is smectogenic plus nematogenic.

- Smectogenic mesophase commences from $\mathrm{C}_{6}$ to $\mathrm{C}_{5}$ homologues for series-1 and $\mathrm{Y}$ respectively whereas it does not commence till the last homologue of series-X.

- Nematogenic mesophase formation commences identically from $\mathrm{C}_{5}$ homologue for series-X and $\mathrm{Y}$ whereas it does not commence till the last member of a present series-1.

- Smectic thermal stability of present series-1 is lower than a series-Y whereas it does not stabilize for series-X.

- Nematic thermal stability of series-X and $Y$ are almost equivalent $(164.6 \approx 163.8)$ whereas it does not stabilize for series-1 of present investigation.

- Upper mesophase length are in increasing order form series-X $>$ Series- $Y>$ series- 1 and the lower mesophase lengths equal for series- $\mathrm{X}$ and $\mathrm{Y}$ and more than series-1, i.e. series- $\mathrm{X}=$ series-Y $>$ series-1.

The exhibition of only smectic or nematic or both mesophases smectic plus nematic is attributed to the suitable magnitudes of anisotropic forces of intermolecular end to end attractions and lateral attractions causing statistically parallel orientational order or/and sliding layered molecular organization for definite range of temperature as result of favorable molecular rigidity and flexibility under floating condition depending upon polarities and/or polarizability of terminal or/and lateral group or groups. Homologous series-1 and $\mathrm{X}$ contain two and one highly polar methoxy $\left(-\mathrm{OCH}_{3}\right)$ groups or group respectively, whose polarity or polarizability as well as trans-cis configuration causes variations in intermolecular cohesion and closeness of magnitudes in more or less proportions. In present case of series-1 which bears one more polar and polarizable lateral $\mathrm{OCH}_{3}$ group as compared to series-X which strengthens the possibility of lamellar packing of molecules from $\mathrm{C}_{6}$ to $\mathrm{C}_{18}$ homologues in their preoccupied crystal lattices which facilitated appearance of smectic mesophase formation either irreversibly or reversibly in monotropic or enantiotropic condition respectively. But in case of series- $\mathrm{X}$ the intermolecular cohesion is undergo reduction with the decreasing number of $-\mathrm{OCH}_{3}$ group of lateral substitution. Therefore end to end attractions predominated to cause the appearance of nematic phase only in case of series-X. The polarity and polarizability of meta substituted $-\mathrm{NO}_{2}$ group being more and the more suitable than the para substituted $-\mathrm{OCH}_{3}$ group which shows the exhibition of smectic plus nematic phase due to the favorable magnitudes of dispersion forces, dipole-dipole interactions, permanent dipole moment across the long molecular axis related to intermolecular cohesion forces of attractions in case of series-Y. The early or late commencement of mesophase or mesophases depends upon the extent of molecular non-coplanarity. The homologous series-X and $\mathrm{Y}$ are more noncoplaner (cis configuration) than present series- 1 which is a little bit more coplanar or less noncoplaner. Therefore mesophase commences from $\mathrm{C}_{5}$ to $\mathrm{C}_{6}$ neighboring homologues. Lowest thermal stability 
(smectic) and the total mesophase lengths of series-1 as compared to series-X and $\mathrm{Y}$ are attributed to its symmetrical trans configuration of homologue molecules. Thus, variations in mesogenic behaviors, properties, and the degree of mesomorphism for the same homologue from series to series are attributed to variations in cis-trans configurations, molecular rigidity and flexibilities, and the changing magnitudes of dipolarities and polarizability of molecules.

\section{Conclusions}

- $\quad$ Present novel series is only smectogenic with low mesophase lengths, low thermal stability and low ordered melting type.

- The group efficiency order derived on the basis of (a) thermal stability (b) early commencement mesophase and (c) total upper and lower mesophase lengths for smectic and nematic are as under.

(a) Smectic: $-\mathrm{NO}_{2}>\left(-\mathrm{OCH}_{3}\right)_{2}>-\mathrm{OCH}_{3}$

Nematic: $-\mathrm{OCH}_{3} \approx-\mathrm{NO}_{2}>\left(-\mathrm{OCH}_{3}\right)_{2}$

(b) Smectic: $-\mathrm{NO}_{2}>\left(-\mathrm{OCH}_{3}\right)_{2}>-\mathrm{OCH}_{3}$

Nematic: $-\mathrm{NO}_{2}=-\mathrm{OCH}_{3}>\left(-\mathrm{OCH}_{3}\right)_{2}$

(c) Smectic + Nematic:

Upper: $-\mathrm{OCH}_{3}>-\mathrm{NO}_{2}>\left(-\mathrm{OCH}_{3}\right)_{2}$

Lower: $-\mathrm{OCH}_{3}=-\mathrm{NO}_{2}>\left(-\mathrm{OCH}_{3}\right)_{2}$

- Mesomorphism is very sensitive and susceptible to a molecular structure.

- Present investigation may be useful for LC devices to be operated at room temperature through study at binary system.

- $\quad$ Presence of chalconyl group being antimicrobial and antifungal and bioactive with presence of added ester group may be useful for reducing consumption of pesticides and insecticides as well as to produce agricultural products of better healthy quality.

- $\quad$ Present investigation has raised and supported conclusions drawn earlier.

\section{Acknowledgements}

Authors acknowledge thanks to the Department of Chemistry (DST-FIST Funded \& UGC-SAP Sponsored), Saurashtra University, Rajkot, for research work. Authors are also thankful to Dr. A.V. Doshi, Ex. Principal M.V.M. Science and Home Science College Rajkot, for his valuable cooperation during present investigation as and when needed. Also thanks to the National Facility for Drug Discovery through New Chemical Entities (NCE's) for analysis of samples.

\section{References}

[1] Reinitzer, F. Monatsh Chem., 9, (1888), 421-441.

[2] Omray, L.K., "Liquid Crystals as novel vesicular delivery system: Current trends in Technology and Science", ISSN: 2279-0535, Vol. II, Issue: VI, A review.

[3] Naemura, S., “Advance LCD technologies”, Displays, 22 (1), (2001).

[4] Kim,W.S., Elston, S.J., \& Raynes, F.P., "Hybrid method for modelling light leakage by a spherical object in a liquid crystal layer” Display, 29 (2008), 458-463.

[5] Talwa, I., Dr.SalnanaShahi, Ramteke, V. \& Syed, I. "Liquid crystal Pharmaceutical Application: A Review", "IJPRAS" International journal of Pharmaceutical Research and Allied Science, 1(2) (2012), 06-11.

[6] Calliste, C.A., Bail, J.C., Trouilas, P., Pouget, C., Chulia.A.J. \& Duroux, L.J. Anticancer Res., 21 (2001), 3949-3956. 
[7] Modzelevska, A., Pettit, C., Achanta, G., Davidson, N.E., Huang, P. \& Khan, S.R., "Anticancer activities of novel chalcone and bischalcone derivatives" Bioorg. Med.Chem, 14 (2006), 3491-3495.

[8] Lee, Y.S., Lim, S.S., Shin, K.H., Kim, Y.S., Ohuchi, K. \& Jung, S.H., "Anti-angiogenic and Anti-tumor Activities of 2'-Hydroxy-4'-methoxychalcone”, Bio.Pharm.Bull, 29 (2006), 10281031 .

[9] Jain, U.K., Bhatiya, R.K., Rao, A.R., Singh, R., Saxena, A.K. \& Seha, I., "Design and Development of Halogenated Chalcone Derivatives as Potential Anticancer Agents" Tropical Journal of Pharmaceutical Research, 13(1) (2014), 73-80.

[10] Gaikwad, P.P., Desai, M.T., "Liquid Crystalline Phase \& its Pharma Applications" International journal of Pharma Research and Review, (2013), 40-52.

[11] Henderson, P.A., Niemeyer, Os., \& Imrie, C.T., Liq. Cryst., 28 (2001), 463-472.

[12] Imrie, C.T. "Liquid crystal dimmers”, Springer, 95 (1999), 149-192.

[13] Gray, G. W., \& Windsor, P.A. Liq. Cryst. Plastic Cryst., Ellis Horwood: Chichester, U.K., 1 (4) (1974), 103-153.

[14] Gray, G. W. "Molecular Structure and the Properties of Liquid Crystal", Academic Press: London. (1962).

[15] Gray, G. W., \& Windsor, P. A., "The role of liquid crystals in life processes by Stewart G.T", Liq. Cryst. and Plastic Cryst., 1 (1974), 308-326.

[16] Gray, G.W. \& Jones, B. "The effect of halogen substitution on the 4-alkoxy benzoic acid", Mesomorphism and chemical constitution part-III, J. of Chem. Soc., (1954), 2556-2562.

[17] Hird, M., Toyne, K. J., Gray, G. W., Day, S. E., \& Mc Donnell, D. G. (1993). Liq. Cryst., 15, 123.

[18] Collings, P.J., \& Hird, M. "Introduction to liquid crystals chemistry and physics", Taylor and Francis Ltd, U.K. (1998).

[19] Marcos, M., Omenat, A., Serrano, J. L. \& Ezcurra, A. (1992). Adv. Mater., 4, 285.

[20] Hird, M., Toyne, K. J., \& Gray, G. W. "Palladium-catalysed cross-coupling reactions in the synthesis of some high polarizability materials" Liq. Cryst., 14(1993), 741-761.

[21] Demus, D., Goodby, J., Gray, G. W., Spiess, H. W. and V. Vill. Eds. V., (1998).Wiley-VCH. Weinheim. 801-833.

[22] Demus, D. "Thermotropic liquid crystals with conventional and unconventional molecular structure" Plenary lectures 100 years of Liquid Crystal Chemistry, Liq. Cry., 5(1989), 75-110.

[23] Demus, D. "Molecular Crystals and Liquid Crystals Incorporating Nonlinear Optics", 100 years of Liquid Crystal Chemistry, Mol. Cryst. Liq. Cry., 165(1988), 45-84.

[24] Chuhan, H. N., \& Doshi, A. V. "The Synthesis and Mesomorphic Properties of a Novel Homologous Series: $\alpha-4-[4$ '-n-Alkoxy benzoyloxy] Benzoyl $-\beta-2$ "-nitro Phenyl Ethylenes" Mol. Cryst. Liq. Cry., 570(1) (2013), 92-110.

[25] Suthar, D.M., Doshi, A.A., \& Doshi, A.V., "Study of Liquid Crystalline State and Evaluation of its Properties Through a Novel Homologous Series”. Mo.Cryst.Liq.Cryst., 582(2013), 7987.

[26] Suthar, D.M., Doshi, A.A., \& Doshi,A.V., "Synthesis and Evaluation of a Novel Liquid Crystalline Homologous Series: $\alpha-4-[4$ '-n-Alkoxy Cinnamoyloxy] Benzoyl- $\beta-3$ ", 4 "Dimethoxy Phenyl Ethylenes", Mo.Cryst.Liq.Cryst., 527(2013), 51-58. 
[27] Marathe, R.B., Vyas, N.N. \& Doshi, A.V. "Molecular Flexibility Operated Mesomorphism" ILCPA, Scipress Ltd., Vol-52 (2015), 163-171.

[28] Tandel, R.C., Gohil, J. \& Patel, N.K. (2012). Res. J. Recent. Sci. Vol.1, ISSC-2011, 122-127.

[29] Patel, B.H., \& Doshi, A.V. "Mesomorphism and Molecular Structure: Novel Homologous Series 4-(4'-n-alkoxy cinnamoyloxy)-4"'-methoxy Benzyl Benzoates” Mol. Cryst. Liq. Cryst., 607(2015), 78-86.

[30] Aurangzeb, H., Asghar A. \& Muhammed, N. A. (2011). Molecules, 16, 7789-7802.

[31] Dave, J. S., \& Vora, R. A., "Liquid Crystal and Ordered Fluids" Plenum Press: New York, (1970), 477.

[32] Patel, R. B., Patel, V. R., \& Doshi, A. V. "Synthesis and Mesomorphism of Novel LiquidCrystalline Isobutyl-p-(p'-n-Alkoxy Cinnamoyloxy) Cinnamates” Mol. Cryst. Liq. Cryst., 552(2012), 3-9.

[33] Greene, T. W. \& Wuts, P. G. M. "Protective Groups in Organic Synthesis" 2nd Ed.; John Wiley and Sons: New York. (1991).

[34] Chauhan, H.N. \& Doshi, A.V. "Study of novel liquid crystals of ethylene derivatives: $\alpha-4-[4$ ' -n-alkoxy cinnamoyloxy] phenyl $\beta-4$ "-methoxy benzoyl ethylenes" Der Pharma Chemica, 4(2) (2012), 731-736.

[35] Chaudhari, R.P. \& Doshi, A.V. "Synthesis of Novel Mesomorphic Homologous Series: $\alpha-4-[-$ 4'-n-Alkoxy cinnamoyloxy] Phenyl- $\beta-3$ " Nitrobenzoyl Ethylenes" Mol. Cryst. Liq. Cryst., 569(2012), 49-56. 